\title{
GTP Binding Is Necessary for the Activation of a Toxic Mutant Isoform of the Essential GTPase ObgE
}

\author{
Liselot Dewachter 1,2, Babette Deckers 3,4 , Ella Martin 1,2 , Pauline Herpels 1,2, Sotirios Gkekas 3,4, \\ Wim Versées ${ }^{3,4}$, Natalie Verstraeten ${ }^{1,2} \mathbb{D}$, Maarten Fauvart ${ }^{1,2,5,+}$ and Jan Michiels ${ }^{1,2, *, \dagger}$ \\ 1 Centre of Microbial and Plant Genetics, KU Leuven-University of Leuven, Kasteelpark Arenberg 20 Box \\ 2460, B-3001 Leuven, Belgium; liselot.dewachter@kuleuven.vib.be (L.D.); ella.martin@vub.be (E.M.); \\ Pauline.herpels@kuleuven.vib.be (P.H.); natalie.verstraeten@kuleuven.vib.be (N.V.); \\ maarten.fauvart@kuleuven.vib.be (M.F.) \\ 2 VIB-KU Leuven Center for Microbiology, Kasteelpark Arenberg 20 Box 2460, B-3001 Leuven, Belgium \\ 3 Structural Biology Brussels, Vrije Universiteit Brussel, Pleinlaan 2, B-1050 Brussels, Belgium; \\ Babette.deckers@vub.be (B.D.); sotosgkekas@gmail.com (S.G.); wim.versees@vub.be (W.V.) \\ 4 VIB-VUB Center for Structural Biology, Pleinlaan 2, B-1050 Brussels, Belgium \\ 5 Imec, Kapeldreef 75, B-3001 Leuven, Belgium \\ * Correspondence: jan.michiels@kuleuven.vib.be \\ $+\quad$ M.F. and J.M. are joint senior authors.
}

Received: 4 November 2019; Accepted: 17 December 2019; Published: 18 December 2019

\begin{abstract}
Even though the Obg protein is essential for bacterial viability, the cellular functions of this universally conserved GTPase remain enigmatic. Moreover, the influence of GTP and GDP binding on the activity of this protein is largely unknown. Previously, we identified a mutant isoform of ObgE (the Obg protein of Escherichia coli) that triggers cell death. In this research we explore the biochemical requirements for the toxic effect of this mutant $\mathrm{ObgE}^{*}$ isoform, using cell death as a readily accessible read-out for protein activity. Both the absence of the N-terminal domain and a decreased GTP binding affinity neutralize $\mathrm{ObgE}^{*}$-mediated toxicity. Moreover, a deletion in the region that connects the $\mathrm{N}$-terminal domain to the $\mathrm{G}$ domain likewise abolishes toxicity. Taken together, these data indicate that GTP binding by $\mathrm{ObgE}^{*}$ triggers a conformational change that is transmitted to the $\mathrm{N}$-terminal domain to confer toxicity. We therefore conclude that ObgE*-GTP, but not ObgE*-GDP, is the active form of $\mathrm{ObgE}^{*}$ that is detrimental to cell viability. Based on these data, we speculate that also for wild-type ObgE, GTP binding triggers conformational changes that affect the N-terminal domain and thereby control ObgE function.
\end{abstract}

Keywords: Obg; ObgE; GTPase; GTP binding; Escherichia coli

\section{Introduction}

Obg proteins belong to the TRAFAC (translation factor) class of P-loop GTPases that typically switch between a GTP- and a GDP-bound state by GTP hydrolysis or nucleotide exchange [1,2]. Because the GTP hydrolysis rate of Obg is low and nucleotide exchange occurs very fast, the nucleotide binding state of Obg is thought to be mainly controlled by the intracellular ratio of GTP and GDP [2-5]. Interestingly, Obg also binds ppGpp with physiologically relevant affinity [6,7].

Obg GTPases generally consist of three distinct domains. The N-terminal Obg domain is widely conserved and is essential for Obg function [2,8]. It consists of six left-handed type II helices and an eight-stranded $\beta$-barrel that contacts the $G$ domain [8-10]. The Obg domain most likely mediates protein-protein interactions with effector molecules $[8,11]$. In Escherichia coli Obg (ObgE), this domain spans from amino acid residue 1 until 157 [9]. Nucleotide binding and hydrolysis is performed by 
the G domain. This domain consists of a six-stranded $\beta$-sheet and five $\alpha$-helices and undergoes conformational changes in response to nucleotide binding [1,2,8-10]. These conformational changes are thought to be transmitted to the $\mathrm{N}$ terminus through a flexible linker region between the $\mathrm{G}$ and $\mathrm{N}$ domains [8,12]. In E. coli, the $\mathrm{G}$ domain contains amino acid residues 158 to 340 [9]. The final 50 residues of ObgE make up the C-terminal domain [9]. This domain is not well conserved among different species and is therefore thought to mediate species-specific Obg functions [2]. In E. coli, the C-terminus of ObgE is intrinsically disordered [9].

The Obg protein is widely-conserved and essential for viability in all bacteria tested to date [2]. It plays a role in a variety of important cellular processes, such as ribosome assembly, the stringent response, morphological development, and antibiotic tolerance [2,6,13-15]. Its essential function, however, is thought to stem from its involvement in cell cycle progression, where it has been shown to influence the initiation of DNA replication, chromosome segregation, and cell division [2,16-20]. None of these roles of Obg have been characterized mechanistically, leaving the exact molecular functions of Obg enigmatic. Moreover, although Obg is a GTPase with distinct structural domains, the effect of nucleotide binding on protein function remains largely unexplored and it is unclear which protein domains contribute to specific functions.

Here, we set out to help bridge the gap between the in vitro structural and biochemical data on the ObgE protein and its in vivo behavior. More specifically, we investigate the influence of different protein domains and nucleotide binding on the toxic effect of a mutant isoform of ObgE, called ObgE* $\mathrm{ObgE}^{*}$ contains a K268I amino acid substitution, which is located in the G domain of the protein $[19,21]$. This mutant protein causes a severe loss of viability in E. coli, thereby providing an easy way to assess one aspect of $\mathrm{ObgE}$ activity $[19,21]$. Our results indicate that, besides the mutated G domain, also the $\mathrm{N}$-terminal domain of $\mathrm{ObgE}^{*}$ is necessary to confer toxicity. Moreover, the integrity of the linker region between both domains appears to be essential. Additionally, we observed that mutations that lead to a decreased GTP binding affinity rescue the toxic effect of ObgE* . These data suggest that the conformational change that occurs upon GTP binding needs to be correctly transmitted to the $\mathrm{N}$-terminal Obg domain in order for $\mathrm{ObgE}^{*}$ to exert its toxic effect. Our findings thus indicate that the toxic activity of $\mathrm{ObgE}^{*}$ in vivo depends on its nucleotide binding state and that information on this nucleotide binding state is transmitted to the N-terminal Obg domain to influence protein activity.

\section{Results}

\subsection{The N-Terminal and G Domains of ObgE* Are Necessary for Toxicity}

The K268I substitution is responsible for the dominant negative effect of $\mathrm{ObgE}^{*}$. ObgE* causes cell death in E. coli even at very low expression levels despite the presence of the chromosomally-expressed wild-type ObgE protein [21]. The K268I mutation is situated in the G domain of the protein. We therefore wondered whether this mutated $G$ domain is sufficient to lower viability. To answer this question, expression vectors were constructed that encode only the $G$ domain $(G)$, the N-terminal and $G$ domains (NG), or the $G$ and C-terminal domains (GC) of both $\mathrm{ObgE}$ and $\mathrm{ObgE}^{*}$. Survival upon expression of the $\mathrm{ObgE}^{*}$ constructs was measured and compared to survival in the presence of the full-length protein (NGC). As is clear from Figure 1, $\mathrm{ObgE}^{*}$ toxicity is completely abolished when only the mutated G domain is expressed. The $\mathrm{G}$ domain by itself is thus insufficient to lower viability. Likewise, the combination of the mutated $\mathrm{G}$ domain with the $\mathrm{C}$-terminal domain has no negative effect on survival. When the N-terminal domain and G domain are combined, however, survival strongly decreases. Interplay between the N-terminal Obg domain and the GTPase domain is thus necessary for ObgE* to exert its toxic effect. Although the C-terminal domain is not necessary for toxicity, its presence can further decrease survival \pm five-fold. 


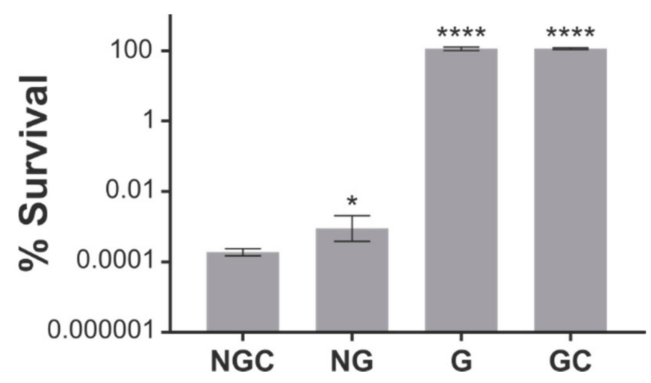

Figure 1. ObgE*-mediated toxicity requires both the $\mathrm{N}$-terminal and $\mathrm{G}$ domains of $\mathrm{ObgE}^{*}$. Survival was determined by dividing the number of CFUs per $\mathrm{mL}$ obtained after expression of ObgE* domain mutants by the number of CFUs per $\mathrm{mL}$ after expression of the corresponding wild-type ObgE domain mutant (NGC, full-length protein; NG, the N-terminal and G domains; G, the G domain; GC, the G and C-terminal domains). Data are represented as averages \pm SEM, $n \geq 3\left({ }^{*} p<0.05,{ }^{* * * *} p<0.0001\right.$, compared to NGC).

\subsection{ObgE* Toxicity Is Influenced by Its Nucleotide Binding State}

ObgE is capable of binding GTP, GDP, and ppGpp and can also weakly catalyze the hydrolysis of GTP [2,3]. By using an array of amino acid substitutions that alter ObgE's nucleotide binding affinities [7], we investigated the effect of the nucleotide binding state of $\mathrm{ObgE}^{*}$ on toxicity. All amino acid substitutions used are listed in Table 1, together with their effect on the affinity of ObgE for GDP, the non-hydrolysable GTP analog GTP $\gamma \mathrm{S}$ and $\mathrm{ppGpp}$. The location of these amino acid residues in the ObgE protein is shown in Figure S1. The genetic changes underlying these amino acid alterations were introduced in $o b g E^{*}$ and their effect on toxicity was determined.

Table 1. Nucleotide binding affinities (equilibrium dissociation constants, $K_{D}$ in $\mu M$ ) of wild-type and mutant ObgE proteins. Equilibrium dissociation constants $\left(\mathrm{K}_{\mathrm{D}}\right)$ ( \pm fitting error) were determined by isothermal titration calorimetry (ITC). The three right columns give the ratios of the $K_{D}$ values for different nucleotides. NMB, no measurable binding.

\begin{tabular}{|c|c|c|c|c|c|c|}
\hline & \multicolumn{3}{|c|}{ Equilibrium Dissociation Constants } & \multicolumn{3}{|c|}{ Ratios } \\
\hline & $K_{D}(G D P)$ & $K_{D}(G T P \gamma S)$ & $K_{D}(p p G p p)$ & $\begin{array}{c}K_{D}(G D P) / \\
K_{D}(p p G p p)\end{array}$ & $\begin{array}{c}\mathrm{K}_{\mathrm{D}}(\mathrm{GTP} \gamma \mathrm{S}) / \\
\mathrm{K}_{\mathrm{D}}(\mathrm{GDP})\end{array}$ & $\begin{array}{l}K_{D}(G T P \gamma S) \\
K_{D}(p p G p p)\end{array}$ \\
\hline Wildtype $^{\mathrm{a}}$ & $0.44 \pm 0.03$ & $1.3 \pm 0.1$ & $0.63 \pm 0.08$ & 0.70 & 3.0 & 2.1 \\
\hline $\mathrm{G}^{166 \mathrm{~V}^{\mathrm{a}}}$ & NMB & NMB & NMB & NMB & NMB & NMB \\
\hline $\mathrm{T} 174 \mathrm{I}$ & $115 \pm 2$ & $160 \pm 11$ & $81 \pm 3$ & 1.4 & 1.4 & 2.0 \\
\hline $\mathrm{T}_{193 \mathrm{~A}^{\mathrm{a}}}$ & $0.53 \pm 0.03$ & $4.7 \pm 0.4$ & $0.8 \pm 0.1$ & 0.66 & 8.9 & 5.9 \\
\hline $\mathrm{D} 246 \mathrm{G}^{\mathrm{a}}$ & $4.1 \pm 0.4$ & $14.8 \pm 0.9$ & $7.8 \pm 1.2$ & 0.53 & 3.6 & 1.9 \\
\hline S270I ${ }^{a}$ & $0.45 \pm 0.05$ & $4.9 \pm 0.5$ & $1.14 \pm 0.09$ & 0.39 & 11 & 4.3 \\
\hline $\mathrm{N} 283 \mathrm{I}^{\mathrm{a}}$ & NMB & NMB & NMB & NMB & NMB & NMB \\
\hline $\mathrm{D} 286 \mathrm{Y}^{\mathrm{a}}$ & NMB & NMB & NMB & NMB & NMB & NMB \\
\hline
\end{tabular}

First, as is shown in Figure 2A, the introduction of amino acid substitutions that abolish nucleotide binding (G166V, N283I, and D286Y) completely neutralizes ObgE*-mediated toxicity. We therefore conclude that nucleotide binding is a prerequisite for $\mathrm{ObgE}^{* \prime} \mathrm{s}$ toxic activity.

After establishing that nucleotide binding is necessary for $\mathrm{ObgE}^{*}$-mediated toxicity, we set out to identify which nucleotide-binding state of $\mathrm{ObgE}^{*}$ is responsible for lowering viability. Therefore, the effect of the T174I, T193A, D246G, and S270I amino acid substitutions on ObgE*-mediated toxicity was determined. These amino acid substitutions influence binding of GTP, GDP, and ppGpp in different ways and can therefore be used to determine which nucleotide $\mathrm{ObgE}^{*}$ needs to bind to exert its toxic effect. As shown in Supplementary Figure S2, ObgE* toxicity is unaltered in a $\Delta$ relA $\Delta$ spoT strain that is unable to synthesize (p)ppGpp, thereby conclusively eliminating any role for (p)ppGpp binding in $\mathrm{ObgE}^{*}$ toxicity. Moreover, there is no clear correlation between viability and the individual binding affinities for GDP, GTP, or ppGpp (Figure S2). However, rather than looking at the absolute effect of 
these mutations on the affinity for each nucleotide separately, it should be kept in mind that in an in vivo setting the overall average nucleotide-bound state of $\mathrm{ObgE}$ is determined by the ratio of its binding affinities for the different nucleotides. For example, if the GTP binding affinity of a certain ObgE mutant lowers two-fold, but its affinity for GDP is decreased by a factor 10, we expect the in vivo ratio of GTP- versus GDP-bound protein to be shifted towards the GTP-bound state. We therefore determined changes in the equilibrium binding state of ObgE mutants by calculating the ratio of individual binding affinities (Table 1). No correlation between toxicity and the ratio of the equilibrium dissociation constants $\left(\mathrm{K}_{\mathrm{D}}\right)(\mathrm{GDP}) / \mathrm{K}_{\mathrm{D}}(\mathrm{ppGpp})$ can be found (Figure $\left.2 \mathrm{~B}\right)$. However, when looking at the $K_{D}(G T P) / K_{D}(G D P)$ and the $K_{D}(G T P) / K_{D}(p p G p p)$ ratios, clear correlations emerge (Figure $\left.2 C, D\right)$. In both cases, the higher these ratios are-and thus the more the equilibrium is shifted away from the GTP-bound state-the higher the viability upon $\mathrm{ObgE}^{*}$ expression is. We therefore conclude that ObgE* confers toxicity mainly in its GTP-bound form.

A

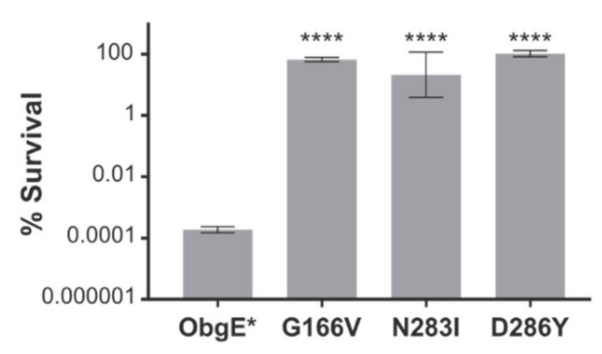

C

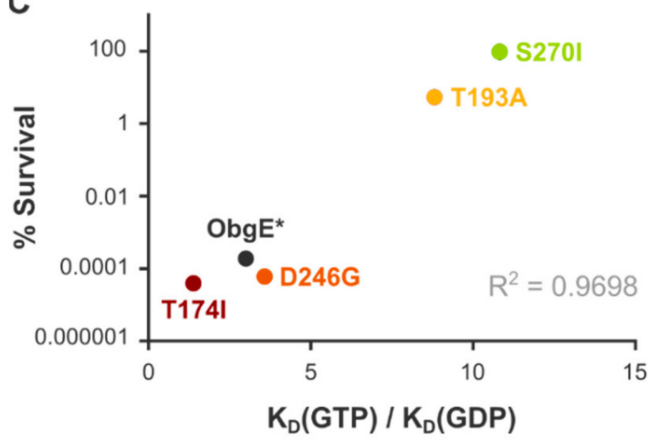

Equilibrium away from GTP binding

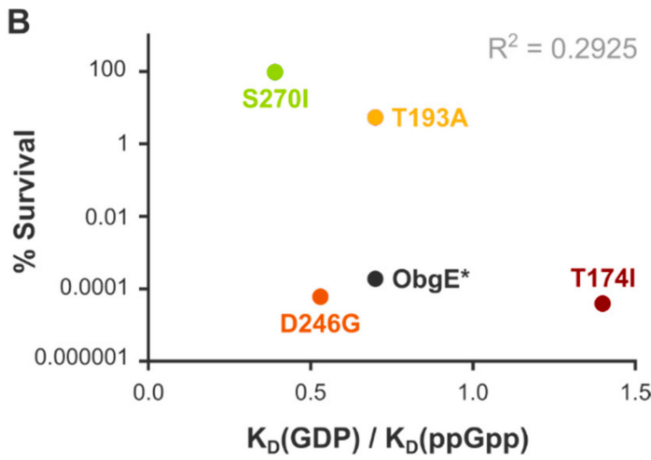

D

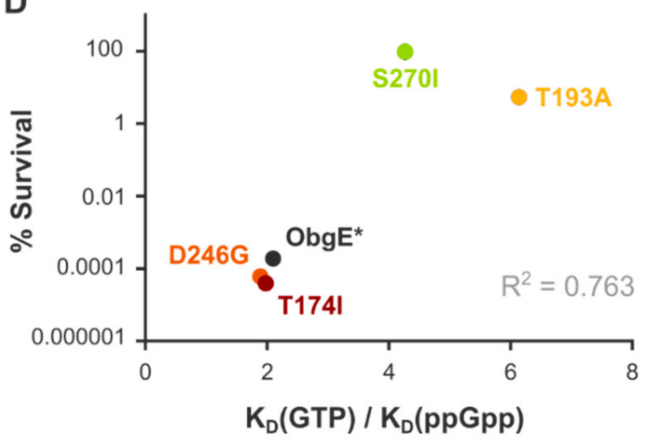

Equilibrium away from GTP binding

Figure 2. $\mathrm{ObgE}^{*}$ needs to bind GTP to confer toxicity. (A) Survival was determined upon expression of $\mathrm{ObgE}^{*}$ and several $\mathrm{ObgE}^{*}$ mutants that are unable to bind nucleotides. Survival is calculated by dividing the number of CFUs per $\mathrm{mL}$; obtained after expression of $\mathrm{ObgE}^{*}$ or $\mathrm{ObgE}^{*}$ mutants by the number of CFUs per $\mathrm{mL}$ obtained after expression of wild-type ObgE. Data are represented as averages $\pm \mathrm{SEM}$, $n \geq 3$ (**** $p<0.0001$, compared to $\mathrm{ObgE}^{*}$ ). (B) Survival upon expression of ObgE* mutants with altered nucleotide binding affinity was measured and is shown as a function of the $K_{D}(G D P) / K_{D}$ (ppGpp) ratio of the ObgE mutants. The higher this value, the more the equilibrium is shifted away from GDP binding towards ppGpp binding. (C) Survival upon expression of $\mathrm{ObgE}^{*}$ mutants with altered nucleotide binding affinity was measured and is shown as a function of the $\mathrm{K}_{\mathrm{D}}(\mathrm{GTP}) / \mathrm{K}_{\mathrm{D}}(\mathrm{GDP})$ ratio of the $\mathrm{ObgE}$ mutants. The higher this value, the more the equilibrium is shifted away from GTP binding towards GDP binding. (D) Survival upon expression of $\mathrm{ObgE}^{*}$ mutants with altered nucleotide binding affinity was measured and is shown as a function of the $\mathrm{K}_{\mathrm{D}}(\mathrm{GTP}) / \mathrm{K}_{\mathrm{D}}(\mathrm{ppGpp})$ ratio of the ObgE mutants. The higher this value, the more the equilibrium is shifted away from GTP binding towards ppGpp binding. $\mathrm{R}^{2}$, squared Pearson correlation coefficient. 
An alternative explanation for the absence of toxicity in $\mathrm{ObgE}^{*}$ mutants with abolished or altered nucleotide binding is that the selected mutations lead to decreased expression and/or increased degradation. A Western blot analysis of these mutants shows that this is not the case (Figure S3A). Alternatively, the mutations present could prevent correct folding of the $\mathrm{ObgE}^{*}$ protein and therefore no longer lead to a decrease in viability. To exclude this possibility, we took advantage of ObgE being essential for viability [2,3]. We assessed whether the non-toxic $o b g E^{*}$ alleles $\left(o b g E^{*}{ }_{\mathrm{G} 166 \mathrm{~V}}, o b g E^{*}\right.$ S270I $o b g E^{*}{ }_{\mathrm{N} 283 \mathrm{I}}$, and $o b g E^{*} \mathrm{D} 286 \mathrm{Y}$ ) could function as the sole copy of ObgE in E. coli. While expression of these mutant alleles was induced from a plasmid, the chromosomal wild-type obgE gene was deleted. With the exception of $o b g E^{*} \mathrm{G} 166 \mathrm{~V}$, all non-toxic $o b g E^{*}$ alleles could still support viability and are thus correctly folded (Figure S3B). The lack of toxicity upon expression of these mutants can thus be attributed to their changed nucleotide binding affinities.

\subsection{Altering the Linker Region between the N-Terminal and G Domains of ObgE* Neutralizes Toxicity}

To identify additional genetic changes in $o b g E^{*}$ capable of neutralizing toxicity, we generated spontaneous compensatory mutations. In order to do so, we induced $\mathrm{Obg} \mathrm{E}^{*}$-Venus expression on plate and scored colony development. The fluorescent fusion protein $\mathrm{ObgE}^{*}$-Venus retains full toxicity [19] and was used to enable a counter selection against non-fluorescent mutants in which $\mathrm{ObgE}^{*}$ expression is abolished. Yellow fluorescent colonies correspond to mutants that express full-length $\mathrm{ObgE}^{*}$ but are still able to grow. These colonies were selected and their ObgE*-Venus-encoding plasmids were isolated and transformed into a new E. coli strain. In this fresh background, the absence of toxicity upon induction of $\mathrm{ObgE}^{*}$ was confirmed to eliminate strains that are resistant to $\mathrm{ObgE}^{*}$ expression due to chromosomal mutations. This way, we selected plasmids that carry compensatory mutations in $o b g E^{*}$. Initially, 20 such plasmids-originating from 10 independent overnight cultures-were isolated and sequenced. No single-nucleotide polymorphisms were detected in the selected plasmids. All plasmids did, however, contain the exact same 12-bp deletion in the obgE* gene. This in-frame deletion results in the elimination of amino acid residues LLEL spanning position 153 to 156 in the $\mathrm{ObgE}^{*}$ protein. The positions of the deleted residues are highlighted in Figure 3.

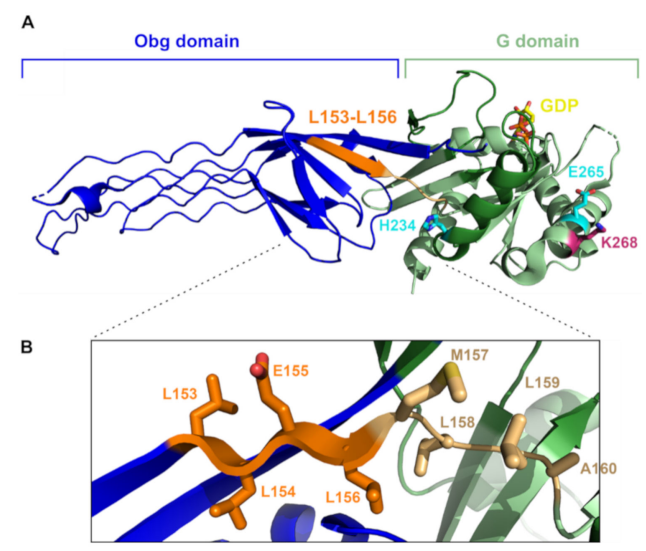

Figure 3. Crystal structure of ObgE showing the position of amino acid changes that neutralize $\mathrm{ObgE}^{*}$-mediated toxicity. (A) Schematic representation of the crystal structure of ObgE lacking the C-terminal domain. The N-terminal Obg domain is shown in blue, while the G domain of the protein is highlighted in green. The switch I and II regions are colored in a darker shade of green and the bound GDP molecule is shown in yellow. The K268 residue that is mutated in $\mathrm{ObgE}^{*}$ is indicated in pink. The four amino acids that are deleted in many spontaneous compensatory mutants are highlighted in orange (LLEL, positions 153 to 156). Some of the other compensatory mutations are shown in cyan (H234 and E265). (B) A close-up view of the region connecting the Obg and G domains. The four amino acids that are deleted in many spontaneous compensatory mutants (LLEL, positions 153 to 156) are directly followed by a rather similar motif in the linker region that connects the Obg and G domains 
(MLLA). We hypothesize that the MLLA stretch of the linker region can replace the deleted LLEL residues of the last $\beta$-strand in the $\beta$-barrel subdomain, which otherwise would most likely be deleterious to the fold. If true, the linker between the Obg and G domain is shortened in the $\Delta 153-156$ mutant, which could affect the movement of both domains relative to each other.

It is striking that all $20 \circ b g E^{*}$ alleles contain the exact same 12-bp deletion and that no other mutations were selected, especially since several $\mathrm{ObgE}^{*}$ mutant proteins were identified that no longer cause toxicity (Figure 2). A possible explanation for why only this 12-bp deletion was selected is that it arises more easily than other types of mutations. The detected deletion in $o b g E^{*}$ occurs in a region with repeated CTG codons. Such repetitive sequences are extremely sensitive to replication errors and are often deleted during replication [22]. Deletions in this region might therefore occur more frequently, which could explain why only this non-toxic allele was isolated. To circumvent this issue, we altered the repeated CTG codons in this region to synonymous but non-identical codons.

\subsection{Spontaneous Mutations in ObgE* That Neutralize Toxicity Also Decrease GTP Binding}

Starting from the $o b g E^{*}$-venus construct with unique codons for amino acids 153 to 156 , we again isolated spontaneous compensatory mutations in $o b g E^{*}$. Out of the nine mutant $o b g E^{*}$ alleles sequenced, five carried a reversion of the original K268I mutation (Table 2), indicating that the easiest and/or best way to counteract $\mathrm{ObgE}^{*}$-mediated toxicity is to eliminate the causative mutation and revert to wild-type ObgE. Four additional mutations that can likewise neutralize toxicity were identified (Table 2). One of them is again an in-frame deletion in a highly repetitive genetic region in the G domain, highlighting the sensitivity of such repetitive regions to replication errors. Two other mutations affect the glutamic acid residue at position 265 and change it to aspartic acid or lysine. Finally, also the substitution of histidine by arginine at position 234 can counteract $\mathrm{ObgE}^{*}$ toxicity (Figure 3A).

Table 2. Spontaneous compensatory mutations that neutralize ObgE*-mediated toxicity. Reference sequence based on $\operatorname{obg} E^{*}$. AA, amino acid. Bp, base pairs. SNP, single nucleotide polymorphism.

\begin{tabular}{ccccc}
\hline Type & Reference Sequence & Allele & AA Change & Frequency Found \\
\hline SNP & ATA & AAA & I268K & $5 / 9$ \\
SNP & CAC & CGC & H234R & $1 / 9$ \\
SNP & GAG & GAT & E265D & $1 / 9$ \\
SNP & GAG & AAG & E265K & $1 / 9$ \\
Deletion, $6 \mathrm{bp}$ & GAA AGC & - & $\Delta_{298-299} \mathrm{KA}$ & $1 / 9$ \\
\hline
\end{tabular}

As was done for the ObgE mutants with known nucleotide binding affinities, we confirmed expression levels and proper folding of the $o b g E^{*}$ alleles selected here by assessing their capability to support growth (Figure S3). Perhaps not surprisingly, the $\mathrm{ObgE}^{*} \Delta 153-156 \mathrm{LLEL}$ protein is incapable of supporting viability and $\mathrm{ObgE}^{*}{ }_{2298-299 E S}$ allows only limited growth. We can therefore not be sure that these mutant proteins are properly folded. The other mutants are fully capable of supporting viability and thus fold correctly.

To assess the influence of a selection of these mutations on nucleotide binding, we purified $\mathrm{ObgE}_{\Delta 153-156}, \mathrm{ObgE}_{\mathrm{H} 234 \mathrm{R}}$, and $\mathrm{ObgE} \mathrm{E}_{\mathrm{E} 265 \mathrm{~K}}$. SDS-PAGE gels of the purified proteins are shown in Figure S4. We then performed isothermal titration calorimetry and determined equilibrium binding constants of these mutant proteins (Figure S5). Although the $\mathrm{K}_{\mathrm{D}}(\mathrm{GDP}) / \mathrm{K}_{\mathrm{D}}(\mathrm{ppGpp}$ ) value is more or less constant in these mutants, the equilibrium is clearly shifted towards lower GTP binding in all of them (Table 3). These data thus indicate that the H234R and E265K substitutions eliminate toxicity by lowering GTP binding. These results therefore confirm our previous findings from rationally selected ObgE mutants that show that GTP binding is essential for $\mathrm{ObgE}^{*}$-mediated toxicity (Figure 2). Moreover, the $\mathrm{ObgE}_{\Delta 153-156}$ mutant protein shows a moderate decrease in GTP binding which is expected to 
contribute to neutralizing ObgE ${ }^{*}$ toxicity. However, since the effect of the $\Delta 153-156$ deletion on the nucleotide binding ratios is rather small, we suspect other factors to be at play as well (see Discussion).

Table 3. Nucleotide binding affinities (equilibrium dissociation constants, $K_{D}$ in $\mu \mathrm{M}$ ) of wild-type $\mathrm{ObgE}$ and spontaneous compensatory mutant ObgE proteins. Equilibrium dissociation constants $\left(\mathrm{K}_{\mathrm{D}}\right)$ ( \pm fitting error) were determined by isothermal titration calorimetry (ITC). The three right columns give the ratios of the $K_{D}$ values for different nucleotides. $\mathrm{NMB}$, no measurable binding.

\begin{tabular}{|c|c|c|c|c|c|c|}
\hline & \multicolumn{3}{|c|}{ Equilibrium Dissociation Constants } & \multicolumn{3}{|c|}{ Ratios } \\
\hline & $K_{D}(G D P)$ & $K_{D}(G T P \gamma S)$ & $K_{D}(p p G p p)$ & $\begin{array}{c}\mathrm{K}_{\mathrm{D}}(\mathrm{GDP}) / \\
\mathrm{K}_{\mathrm{D}}(\mathrm{ppGpp})\end{array}$ & $\begin{array}{c}\mathrm{K}_{\mathrm{D}}(\mathrm{GTP} \gamma \mathrm{S}) / \\
\mathrm{K}_{\mathrm{D}}(\mathrm{GDP})\end{array}$ & $\begin{array}{c}K_{D}(G T P \gamma S) \\
K_{D}(p p G p p)\end{array}$ \\
\hline Wildtype $^{\mathrm{a}}$ & $0.44 \pm 0.03$ & $1.3 \pm 0.1$ & $0.63 \pm 0.08$ & 0.70 & 3.0 & 2.1 \\
\hline$\Delta 153-156$ & $0.60 \pm 0.05$ & $3.4 \pm 0.5$ & $0.64 \pm 0.06$ & 0.94 & 5.7 & 5.3 \\
\hline $\mathrm{H} 234 \mathrm{R}$ & $0.43 \pm 0.05$ & $3.7 \pm 0.5$ & $0.60 \pm 0.06$ & 0.72 & 8.6 & 6.2 \\
\hline E265K & $0.25 \pm 0.03$ & $5.7 \pm 0.8$ & $0.31 \pm 0.03$ & 0.81 & 23 & 18 \\
\hline
\end{tabular}

\section{Discussion}

In this study we present evidence that implies that $\mathrm{ObgE}^{*}$-mediated cell death is triggered by the GTP-bound version of the protein. Since the G domain itself is insufficient to cause toxicity, we postulate that GTP binding by $\mathrm{ObgE}^{*}$ leads to changes in the N-terminal domain that trigger cell death.

Although the mutated residue of $\mathrm{ObgE}^{*}, \mathrm{~K} 268$, is located in the $\mathrm{G}$ domain, expression of this mutated domain is not sufficient to cause cell death. Rather, a combination of the N-terminal and G domains is necessary to confer toxicity (Figure 1). It therefore follows that interaction between the mutated $G$ domain and the N-terminus leads to a loss of viability by ObgE*. The C-terminal domain, on the other hand, is not essential for $\mathrm{ObgE}^{*}$-mediated cell death, although its presence can increase toxicity by a factor 5. The ObgE C-terminus is intrinsically disordered [9], but could possibly fold upon target binding [23]. This domain could thus influence the stability and/or function of ObgE* and thereby contribute to $\mathrm{ObgE}^{*}$-mediated toxicity. However, other explanations for the role of the C-terminal domain in $\mathrm{ObgE}^{*}$ toxicity are possible (see below).

Mutations that abolish nucleotide binding neutralize ObgE*-mediated toxicity completely. To assess which nucleotide binding state is responsible for toxicity, we measured survival upon expression of rationally selected $\mathrm{ObgE}^{*}$ mutant proteins with altered binding affinities. The effects of the mutations on the binding affinity for the different nucleotides suggest that $\mathrm{ObgE}^{*}$ needs to bind GTP to exert its toxic effect (Figure 2). Moreover, we also selected spontaneous mutations that counteract $\mathrm{ObgE}^{*}$ toxicity and confirmed that they have a similar effect on GTP binding (Table 3). These two independent and complementary experiments thus both point towards an important role for GTP binding in $\mathrm{ObgE}^{*}$ activity. We conclude that, besides the presence of the N-terminal domain, GTP binding is also a prerequisite for $\mathrm{ObgE}^{*}$-mediated cell death.

Since the N-terminal domain of $\mathrm{ObgE}^{*}$ is essential for toxicity, we would expect that also mutations in this part of the protein could neutralize toxicity, for example by blocking binding to a downstream effector protein. However, no such mutations were isolated when looking for compensatory mutations in $\operatorname{obg} E^{*}$. We therefore suspect that our screen was not saturating and that still other mutations could be isolated that neutralize toxicity.

Interestingly, it was shown previously that deletion of the C-terminus decreases GTP binding affinity 10-fold, while having only very little effect on GDP or ppGpp binding [9]. The increased affinity for GTP in the presence of the C-terminal domain could explain the C-terminus' capability to modestly increase toxicity. It is therefore possible that the C-terminus has no structural role in toxicity but rather decreases survival upon ObgE* expression by increasing GTP binding. 
An alternative explanation for the observed data is that not GTP binding, but rather GTP hydrolysis triggers $\mathrm{ObgE}^{*}$-mediated cell death. However, we deem this explanation very unlikely since GTP hydrolysis by the ObgE protein was shown to occur very slowly [2,5]. Moreover, it was shown previously that ObgE's GTP hydrolysis rate is lowered by the introduction of the D246G mutation [7]. This mutation does not have any effect on $\mathrm{ObgE}^{*}$-mediated cell death, further indicating that toxicity is not linked to GTP hydrolysis.

As a GTPase, ObgE most likely adopts different conformations depending on the nucleotide-bound state $[1,8-10]$. However, these different conformations have not yet been observed experimentally $[8,9]$. The 4-amino-acid deletion of residues LLEL at position 153-156 that neutralizes ObgE*-mediated toxicity is located at the interface between the $\mathrm{N}$-terminal and $\mathrm{G}$ domains. This region corresponds to the $\mathrm{C}$-terminal residues of the last $\beta$-strand in the $\beta$-barrel subdomain of the Obg domain of the ObgE structure, just adjacent to the linker region connecting the Obg domain with the G domain [9]. A deletion in such a $\beta$-strand might seem deleterious to the fold at first sight. However, we noted that the deleted LLEL region is followed by a rather similar MLLA motif in the linker region (Figure 3). We therefore hypothesize that in the deletion mutant, the deleted $\beta$-strand region could be replaced by this particular part of the linker between the $\mathrm{N}$ and $\mathrm{G}$ domains, in effect resulting in a shortened linker region. This shortened linker could influence the movement of the N and G domains relative to each other and thereby affect the conformation adopted by $\mathrm{ObgE}^{*}$ [12]. Due to GTP-bound ObgE* triggering a drop in viability, we suspect that the corresponding conformation of the N-terminal domain confers toxicity. When residues 153 to 156 are deleted from the protein, $\mathrm{ObgE}^{*}$ is probably prevented from adopting this harmful conformation.

Taken together, this study shows how altered nucleotide binding can affect the in vivo activity of $\mathrm{ObgE}^{*}$. We have shown that the toxic effect of the mutant $\mathrm{ObgE}^{*}$ protein depends on GTP binding, leading us to hypothesize that certain functions of the wild-type ObgE protein are likewise activated upon binding of GTP. The correct execution of this GTP-dependent functionality is most likely corrupted by the mutation present in $\mathrm{ObgE}^{*}$, leading to cell death. On the other hand, not all functions of $\mathrm{ObgE}$ depend on GTP binding. Most strikingly, we here show that several mutant proteins that are unable to bind nucleotides are still able to support viability (Figure S3). These results indicate that the essential function of ObgE does not depend on nucleotide binding and/or GTP hydrolysis. Moreover, it was recently shown that the induction of the antibiotic-tolerant persistent state by $\mathrm{Obg} E$ is not linked to GTP binding, but more likely depends on GDP and/or ppGpp [7]. It is currently unknown how GTP binding affects the conformation of ObgE. Although crystal structures of Obg proteins from several organisms are available in the apo-form or bound to GDP or ppGpp [8-10], the structure of Obg-GTP has not been resolved yet. However, data presented here indicate that GTP binding to ObgE indeed induces conformational changes that are transmitted to the $\mathrm{N}$-terminal domain to influence protein activity. Further research is necessary to reveal how Obg functionality is controlled by nucleotide binding and which conformation is adopted by Obg when it binds GTP.

\section{Materials and Methods}

\subsection{Strains, Plasmids, and Growth Conditions}

E. coli BW25113 was used for all experiments unless mentioned otherwise. Testing the influence of (p)ppGpp on toxicity was performed with E. coli BW25113 $\Delta$ relA $\triangle$ spoT [13]. pBAD33Gm was used to express all $\mathrm{ObgE}$ and $\mathrm{Obg} \mathrm{E}^{*}$ mutant proteins for in vivo experiments unless mentioned otherwise [19]. The $o b g E$ or $o b g E^{*}$ fragments encoding the $\mathrm{G}$ domain, the $\mathrm{N}$-terminal and $\mathrm{G}$ domains, and the $\mathrm{G}$ and C-terminal domains were amplified from $\mathrm{pBAD} / \mathrm{His} \mathrm{A}-\mathrm{obg} E$ or $\mathrm{pBAD} / \mathrm{His} \mathrm{A}-o b g E^{*}$ [21] by primer pairs SPI12297/12298, SPI12299/12298, and SPI12297/10603, respectively (Table 4). Amplified fragments were digested with EcoRI and HindIII and cloned into pBAD33Gm [19]. pBAD33Gm-obgE*-venus was constructed by amplification of $o b g E^{*}$-venus from pBAD/His A-obgE*-venus [24] with primer pairs SPI10908/10909. Amplified fragments were digested with KpnI and HindIII and ligated into 
pBAD33Gm. obgE* mutant alleles were constructed by introducing site-specific point mutations into pBAD33Gm-obgE* [19] and/or pET28a-obgE by PCR amplification with mismatch primer pairs SPI12307/12308 for G166V, SPI11077/11078 for T174I, SPI11079/11080 for T193A, SPI11083/11084 for D246G, SPI12309/12310 for S270I, SPI12311/12312 for N283I, SPI12313/12314 for D286Y, SPI11085/11086 for D286L, and SPI12315/12316 for I313N. Unique codons for amino acids 153-156 were introduced into pBAD33Gm-obgE*-venus by amplification with mismatch primer pair SPI12303/12304. Spontaneous compensatory mutations were introduced into pET28a-obgE by amplification with mismatch primer pairs SPI12663/12664, SPI12764/12765, and SPI12659/12660 for mutations $\Delta 153-156$, H234R, and E265K, respectively. Prior to the transformation of PCR products to E. coli BW25113, the template DNA was digested with DpnI. Correct construction of all described plasmids was verified by Sanger sequencing. Overnight cultures containing a pBAD33Gm plasmid were diluted 100 times in lysogeny broth (LB) containing gentamicin $(25 \mu \mathrm{g} / \mathrm{mL})$ and incubated at $37^{\circ} \mathrm{C}$ with continuous shaking at $200 \mathrm{rpm}$. When the OD595 $\mathrm{nm}$ reached 0.4 , expression from pBAD33Gm was induced by the addition of $0.2 \%$ arabinose $(\mathrm{w} / \mathrm{v})$.

Table 4. Primers used in this study.

\begin{tabular}{|c|c|}
\hline Name & Sequence $\left(5^{\prime}-3^{\prime}\right)$ \\
\hline SPI10603 & AGCCAAGCTTTTAACGCTTG \\
\hline SPI10908 & CACCGGTACCCACCAGGAGGAATTAACCATGAAGTTTGTTGATGAAGCATCG \\
\hline SPI10909 & AGCCAAGCTTCGAATTCTTA \\
\hline SPI11077 & AAATCGATCTTTATTCGTGCGG \\
\hline SPI11078 & AATAAAGATCGATTTACCCGCG \\
\hline SPI11079 & ACCGCGCTGGTGCCAAGTCTGGGTG \\
\hline SPI11080 & TGGCACCAGCGCGGTAAACGGATAATC \\
\hline SPI11083 & CTGTTGCACCTCATCGGCATCG \\
\hline SPI11084 & TCGATGCCGATGAGGTGCAAC \\
\hline SPI11085 & AAGATCCTGCTGCTGGATAAGGT \\
\hline SPI11086 & CAGCAGCAGGATCTTGTTGAACA \\
\hline SPI11765 & GCGTAGCGCATCAGGCTGATTTGGCGTTTATCATCAGTGACATATGAATATCCTCCTTA \\
\hline SPI11766 & ATCGCAACCCCGCGCAGGCGAATGATTTACGGAGAATAAAGTGTAGGCTGGAGCTGCTTC \\
\hline SPI12297 & TAGCGAATTCGAGCTCAGGAGGAATTAACCATGCTGCTGGCTGACGTCGGTA \\
\hline SPI12298 & AGCCAAGCTTTTAAGCCTGCACGACCGGG \\
\hline SPI12299 & TAGCGAATTCGAGCTCAGGA \\
\hline SPI12303 & GCGAGCTGCTTCTCGAATTGATGCTGCTGGCTGACG \\
\hline SPI12304 & AGCAGCATCAATTCGAGAAGCAGCTCGCGCTTATCG \\
\hline SPI12307 & CGTCGGTATGTTGGTGATGCCAAACGCGG \\
\hline SPI12308 & CCGCGTTTGGCATCACCAACATACCGACG \\
\hline SPI12309 & GAAATATACATCCAGGATCTG \\
\hline SPI12310 & ATCCTGGATGTATATTTCCAG \\
\hline SPI12311 & TTAGTGTTCATCAAGATCGATCTG \\
\hline SPI12312 & ATCGATCTTGATGAACACTAACC \\
\hline SPI12313 & AAGATCTATCTGCTGGATAAGGT \\
\hline SPI12314 & CAGCAGATAGATCTTGTTGAACA \\
\hline SPI12315 & TATCTGAACTCTGCGGCGAG \\
\hline SPI12316 & CGCCGCAGAGTTCAGATAATATTT \\
\hline SPI12659 & TTATCAGCAAGCTGGAAAAATACAG \\
\hline SPI12660 & TTTTCCAGCTTGCTGATAATAATACG \\
\hline SPI12663 & CGAGCTGATGCTGCTGGCTGAC \\
\hline SPI12664 & GCAGCATCAGCTCGCGCTTATCG \\
\hline SPI12764 & СTTCCTGAAGCGCCTGGAACGTTGCCGCGTCCTGT \\
\hline SPI12765 & CGTTCCAGGCGCTTCAGGAAGCGAATGCCCAGACC \\
\hline
\end{tabular}

\subsection{Survival Assay}

To measure survival, cellular viability upon overexpression of $\mathrm{ObgE}$ or $\mathrm{ObgE}^{*}$ was determined. Two hours after induction with arabinose, cultures were serially diluted in $10 \mathrm{mM} \mathrm{MgSO}_{4}$ and plated 
out on selective LB medium containing $1.5 \%$ agar. After overnight incubation at $37^{\circ} \mathrm{C}$, colonies were counted and CFUs were calculated.

\subsection{Identification of Non-Toxic ObgE* Alleles}

Overnight cultures of E. coli BW25113 pBAD33Gm-obgE*-venus were plated on selective medium containing $0.2 \%$ arabinose. After overnight incubation, colonies that displayed yellow fluorescence were transferred to fresh selective plates with $0.2 \%$ arabinose. Plasmids from strains that were able to grow and retained fluorescence were purified and transformed to a fresh E. coli BW25113 background. Transformed E. coli were first selected on medium without arabinose and were then transferred to selective medium with $0.2 \%$ arabinose. Plasmids that had lost the ability to confer toxicity in the presence of arabinose were selected for further analysis. A total of 20 of such plasmids were sent for Sanger sequencing.

\subsection{Identification of ObgE Mutant Alleles That Can Support Viability}

After transformation of E. coli BW25113 with pBAD33Gm-obgE, the chromosomal obgE gene was deleted by homologous recombination according to the protocol developed by Datsenko and Wanner [25] using primers SPI11765 and SPI11766 (Table 4). Deletion of chromosomal obgE was performed in the presence of arabinose, the inducer of expression from the pBAD33Gm plasmid. Afterwards the chromosomal obgE deletion was transferred to E. coli BW25113 containing a pBAD33Gm plasmid encoding a mutant $o b g E$ allele by P1 transduction in the presence of arabinose. Successful deletions were confirmed by PCR. Constructed strains were grown overnight in the presence of arabinose and serial dilutions of these cultures were spotted onto LB agar medium with arabinose or glucose.

\subsection{Expression, Quantification, and Purification of ObgE Proteins}

All pET28a vectors, carrying an open reading frame coding for an N-terminally $\mathrm{His}_{6}$-tagged ObgE protein construct (wild type or mutant form), were transformed into E. coli BL21 (DE3) pLysS $\mathrm{T}_{1}{ }^{\mathrm{R}}$ cells. Cells were grown at $37^{\circ} \mathrm{C}$ in $1 \mathrm{~L}$ cultures of Terrific Broth (TB) medium containing $25 \mu \mathrm{g} / \mathrm{mL}$ kanamycin. When an $\mathrm{OD}_{600 \mathrm{~nm}}$ of 0.8 was reached, cultures were induced with $1 \mathrm{mM}$ of isopropyl $\beta$-D-1-thiogalactopyranoside (IPTG), after which they were further incubated overnight at $25^{\circ} \mathrm{C}$. In case of the $\mathrm{ObgE}_{\mathrm{H} 234 \mathrm{R}}$ and $\mathrm{ObgE}_{\Delta 153-156}$ mutant proteins, a chaperone-induced expression protocol was used. The temperature was lowered to $18^{\circ} \mathrm{C}$ when the cultures reached an $\mathrm{OD}_{600 \mathrm{~nm}}$ of 1 . After $90 \mathrm{~min}, 0.01 \mathrm{M}$ benzylalcohol was added. After growing the cultures for another $30 \mathrm{~min}$, they were induced with $1 \mathrm{mM}$ IPTG and further incubated overnight at $18^{\circ} \mathrm{C}$. Proteins were purified as previously described [9]. In short, all proteins were purified in two steps using $\mathrm{Ni}^{2+}$-NTA affinity chromatography and size exclusion chromatography. During the purification, the proteins were made nucleotide-free through an alkaline phosphatase treatment. In case of the $\mathrm{Obg} \mathrm{E}_{\mathrm{H} 234 \mathrm{R}}$ and $\mathrm{Obg} \mathrm{E}_{\Delta 153-156}$ mutants, an extra chaperone wash step was performed during the $\mathrm{Ni}^{2+}$-NTA affinity chromatography by using a buffer containing $5 \mathrm{mM}$ ATP.

To quantify the expression level of ObgE mutant proteins, a Western blot with anti-ObgE antibody was performed. E. coli was grown until an $\mathrm{OD}_{600 \mathrm{~nm}}$ of 0.2 was reached after which expression from pBAD33Gm was induced with $0.2 \%$ arabinose for $2 \mathrm{~h}$. Cells were harvested and Western blot was performed as described previously [13].

\subsection{Isothermal Titration Calorimetry}

Isothermal titration calorimetry (ITC) was used to determine the equilibrium dissociation constants $\left(\mathrm{K}_{\mathrm{D}}\right)$ and binding stoichiometries $(\mathrm{n})$ of the different ObgE proteins (wild type or mutant) for GDP, ppGpp, and GTP $\gamma$ S. The ITC experiments were performed at $25^{\circ} \mathrm{C}$ on a MicroCal PEAQ-ITC isothermal titration calorimeter (Malvern Panalytical) using a reference power of $10 \mu \mathrm{cal} / \mathrm{s}$. Depending on the affinity, a protein concentration between 50 and $90 \mu \mathrm{M}$ and a ligand concentration between $525 \mu \mathrm{M}$ 
and $4.5 \mathrm{mM}$ were used in the cell and syringe, respectively. All measurements were performed in a buffer containing $20 \mathrm{mM}$ HEPES (pH 7.5), $150 \mathrm{mM} \mathrm{NaCl}, 5 \mathrm{mM} \mathrm{MgCl}$, and $1 \mathrm{mM} \beta$-mercaptoethanol. During each ITC experiment, 18 injections of $2 \mu \mathrm{L}$ were performed, preceded by a test injection of $0.5 \mu \mathrm{L}$. To determine the $\mathrm{K}_{\mathrm{D}}$-values and binding stoichiometries, the obtained data were fit on the single binding site model provided by the MicroCal PEAQ-ITC analysis software. In case of the ObgE $E_{T 174 \mathrm{I}}$ protein, which displayed low binding affinities for all tested nucleotides, only the $K_{D}$-value could be derived from the fit, while the binding stoichiometry was fixed at 1.

Supplementary Materials: Supplementary materials can be found at http://www.mdpi.com/1422-0067/21/1/16/s1.

Author Contributions: Conceptualization, L.D., W.V., N.V., M.F., and J.M.; formal analysis, L.D., B.D., W.V., N.V., M.F., and J.M.; investigation, L.D., B.D., E.M., P.H., and S.G.; writing-original draft preparation, L.D. and B.D.; writing-review and editing, L.D., B.D., W.V., N.V., M.F., and J.M.; visualization, L.D. and B.D.; supervision, L.D., W.V., N.V., M.F., and J.M. All authors have read and agreed to the published version of the manuscript.

Funding: This research was funded by grants from the Research Foundation-Flanders (FWO) (grant G047122N to J.M. and W.V.; grants G0B2515N and G055517N to J.M.), a Strategic Research Program from the VUB (grant SRP34 to W.V.), the Interuniversity Attraction Poles Program initiated by the Belgian Science Policy Office (grant P7/28 to J.M.), and a KU Leuven C1 grant (C16/17/006 to J.M.). S.G. received a fellowship from the Institute for the Promotion of Innovation through Science and Technology in Flanders (IWT). L.D. and B.D. received fellowships from the FWO.

Conflicts of Interest: The authors declare no conflict of interest. The funders had no role in the design of the study; in the collection, analyses, or interpretation of data; in the writing of the manuscript, or in the decision to publish the results.

\section{References}

1. Vetter, I.R.; Wittinghofer, A. The guanine nucleotide-binding switch in three dimensions. Science 2001, 294, 1299-1304. [CrossRef]

2. Verstraeten, N.; Fauvart, M.; Versees, W.; Michiels, J. The universally conserved prokaryotic GTPases. Microbiol. Mol. Biol. Rev. 2011, 75, 507-542. [CrossRef]

3. Kint, C.; Verstraeten, N.; Hofkens, J.; Fauvart, M.; Michiels, J. Bacterial Obg proteins: GTPases at the nexus of protein and DNA synthesis. Crit. Rev. Microbiol. 2014, 40, 207-224. [CrossRef]

4. Lin, B.; Covalle, K.L.; Maddock, J.R. The Caulobacter crescentus CgtA protein displays unusual guanine nucleotide binding and exchange properties. J. Bacteriol. 1999, 181, 5825-5832.

5. Wout, P.; Pu, K.; Sullivan, S.M.; Reese, V.; Zhou, S.; Lin, B.; Maddock, J.R. The Escherichia coli GTPase CgtA cofractionates with the $50 \mathrm{~S}$ ribosomal subunit and interacts with SpoT. a ppGpp synthetase/hydrolase. J. Bacteriol. 2004, 186, 5249-5257. [CrossRef] [PubMed]

6. Persky, N.S.; Ferullo, D.J.; Cooper, D.L.; Moore, H.R.; Lovett, S.T. The ObgE/CgtA GTPase influences the stringent response to amino acid starvation in Escherichia coli. Mol. Microbiol. 2009, 73, 253-266. [CrossRef] [PubMed]

7. Verstraeten, N.; Gkekas, S.; Kint, C.I.; Deckers, B.; Van den Bergh, B.; Herpels, P.; Louwagie, E.; Knapen, W.; Wilmaerts, D.; Dewachter, L.; et al. Biochemical determinants of ObgE-mediated persistence. Mol. Microbiol. 2019, 112, 1593-1608. [CrossRef] [PubMed]

8. Buglino, J.; Shen, V.; Hakimian, P.; Lima, C.D. Structural and biochemical analysis of the Obg GTP binding protein. Structure 2002, 10, 1581-1592. [CrossRef]

9. Gkekas, S.; Singh, R.K.; Shkumatov, A.V.; Messens, J.; Fauvart, M.; Verstraeten, N.; Michiels, J.; Versees, W. Structural and biochemical analysis of Escherichia coli ObgE. A central regulator of bacterial persistence. J. Biol. Chem. 2017, 292, 5871-5883. [CrossRef]

10. Kukimoto-Niino, M.; Murayama, K.; Inoue, M.; Terada, T.; Tame, J.R.; Kuramitsu, S.; Shirouzu, M.; Yokoyama, S. Crystal structure of the GTP-binding protein Obg from Thermus thermophilus HB8. J. Mol. Biol. 2004, 337, 761-770. [CrossRef]

11. Lee, Y.; Bang, W.Y.; Kim, S.; Lazar, P.; Kim, C.W.; Bahk, J.D.; Lee, K.W. Molecular modeling study for interaction between Bacillus subtilis Obg and Nucleotides. PLoS ONE 2010, 5, e12597. [CrossRef] [PubMed] 
12. Chatterjee, A.; Acharjee, A.; Das, S.; Datta, P.P. Deletion analyses reveal insights into the domain specific activities of an essential GTPase CgtA in Vibrio Cholerae. Arch. Biochem. Biophys. 2019, 665, 143-151. [CrossRef] [PubMed]

13. Verstraeten, N.; Knapen, W.J.; Kint, C.I.; Liebens, V.; Van den Bergh, B.; Dewachter, L.; Michiels, J.E.; Fu, Q.; David, C.C.; Fierro, A.C.; et al. Obg and membrane depolarization are part of a microbial bet-hedging strategy that leads to antibiotic tolerance. Mol. Cell 2015, 59, 9-21. [CrossRef]

14. Feng, B.; Mandava, C.S.; Guo, Q.; Wang, J.; Cao, W.; Li, N.; Zhang, Y.; Zhang, Y.; Wang, Z.; Wu, J.; et al. Structural and functional insights into the mode of action of a universally conserved Obg GTPase. PLoS Biol. 2014, 12, e1001866. [CrossRef] [PubMed]

15. Caldon, C.E.; March, P.E. Function of the universally conserved bacterial GTPases. Curr. Opin. Microbiol. 2003, 6, 135-139. [CrossRef]

16. Sikora, A.E.; Zielke, R.; Wegrzyn, A.; Wegrzyn, G. DNA replication defect in the Escherichia coli cgtA(ts) mutant arising from reduced DnaA levels. Arch. Microbiol. 2006, 185, 340-347. [CrossRef] [PubMed]

17. Kobayashi, G.; Moriya, S.; Wada, C. Deficiency of essential GTP-binding protein ObgE in Escherichia coli inhibits chromosome partition. Mol. Microbiol. 2001, 41, 1037-1051. [CrossRef] [PubMed]

18. Foti, J.J.; Persky, N.S.; Ferullo, D.J.; Lovett, S.T. Chromosome segregation control by Escherichia coli ObgE GTPase. Mol. Microbiol. 2007, 65, 569-581. [CrossRef]

19. Dewachter, L.; Verstraeten, N.; Jennes, M.; Verbeelen, T.; Biboy, J.; Monteyne, D.; Perez-Morga, D.; Verstrepen, K.J.; Vollmer, W.; Fauvart, M.; et al. A mutant isoform of ObgE causes cell death by interfering with cell division. Front. Microbiol. 2017, 8, 1193. [CrossRef]

20. Dewachter, L.; Verstraeten, N.; Fauvart, M.; Michiels, J. An integrative view of cell cycle control in Escherichia Coli. FEMS Microbiol. Rev. 2018, 42, 116-136. [CrossRef]

21. Dewachter, L.; Verstraeten, N.; Monteyne, D.; Kint, C.I.; Versees, W.; Perez-Morga, D.; Michiels, J.; Fauvart, M. A single-amino-acid substitution in Obg activates a new programmed cell death pathway in Escherichia coli. MBio 2015, 6, e01935-15. [CrossRef] [PubMed]

22. Levy, D.D.; Cebula, T.A. Fidelity of replication of repetitive DNA in mutS and repair proficient Escherichia coli. Mutat. Res. 2001, 474,1-14. [CrossRef]

23. Dyson, H.J.; Wright, P.E. Intrinsically unstructured proteins and their functions. Nat. Rev. Mol. Cell Biol. 2005, 6, 197-208. [CrossRef] [PubMed]

24. Dewachter, L.; Herpels, P.; Verstraeten, N.; Fauvart, M.; Michiels, J. Reactive oxygen species do not contribute to ObgE*-mediated programmed cell death. Sci. Rep. 2016, 6, 33723. [CrossRef] [PubMed]

25. Datsenko, K.A.; Wanner, B.L. One-step inactivation of chromosomal genes in Escherichia coli K-12 using PCR products. Proc. Natl. Acad. Sci. USA 2000, 97, 6640-6645. [CrossRef] [PubMed] 